2021-03-15

\title{
Snowboarding, motherhood and mobility
}

\author{
Spowart, Lucy
}

http://hdl.handle.net/10026.1/17500

10.1080/11745398.2019.1669472

Annals of Leisure Research

Informa UK Limited

All content in PEARL is protected by copyright law. Author manuscripts are made available in accordance with publisher policies. Please cite only the published version using the details provided on the item record or document. In the absence of an open licence (e.g. Creative Commons), permissions for further reuse of content should be sought from the publisher or author. 


\section{Snowboarding, Motherhood and Mobility}

\section{Lucy Spowart}

Faculty of Health, Medicine and Dentistry, Plymouth University, UK

The John Bull Building, Research Way, Plymouth, PL6 8BU

Lucy.spowart@plymouth.ac.uk 


\title{
Snowboarding, Motherhood and Mobility
}

\begin{abstract}
This paper recounts one mother's story of living a snowboarding lifestyle as she moves from season to season between America and New Zealand with her husband and preschool child. Building upon existing research on migrant tourist workers and 'lifestyle travellers', Fiona's story draws on interview texts, diary entries, researcher field_notes, and the authors' own experiences as a mother and snow sport migrant, to explore some of the underlying discourses and assumptions associated with motherhood, mobility and leisure. The paper highlights the ways in which social, political and economic changes have blurred the boundaries between work and leisure. Fiona actively draws on neoliberal discourses of individualism and sub-cultural discourses of snowboarding, lifestyle and feminism to craft her 'self' in complex and often contradictory ways. The findings provide a new account of global sport mobility, adding to the research on sport and motherhood and sport migration studies.
\end{abstract}

Keywords: motherhood; snowboarding; lifestyle mobilities; seasonal migration; parenthood; neoliberalism

\section{Prologue}

It is 10 o'clock at night, the interview commences. A child appears, blinking in the bright light. Arms outstretched, he runs to mum. She picks him up, smiles and offers him a biscuit. 'I've not seen him all day' she explains. They play together, for this is their time. Today, it is all that remains. 'Tomorrow we will go up the mountain together'. He smiles. (Field notes)

I must confess, despite all of my preparation, I was not really 'ready' for my interview with Fiona that cold night in September. Needless to say, I had my dicta-phone, my notebook and pencil, spare batteries and scribbled notes. I had collected Fiona's diary a week previously, and had undertaken an initial analysis of her writings. I clutched the diary in my hand, for this was my reason for being here. I was keen to delve a little deeper into some of Fiona's thoughts about snowboarding, but particularly, to explore how Fiona combined a life of mobility, and shift work with the demands of motherhood. The events that unfolded that evening left a lasting impression 
on me.

Initially, I struggled to find Fiona's rented flat in the darkness, for it was located at the far end of an unlit track, a few miles out of town. I had been asked to come at ten o'clock after Fiona's shift had finished at the snowboard shop in town. There were no lights on when I arrived, and I wondered whether I was in the wrong place. 'Surely a family of three doesn't live in here?' I pondered. The outside looked more like a shed than a home. There were no signs that it was lived in, no curtains, no children's toys outside, no give away clues. I knocked on the door. There was no reply. Yet, I knew someone should be in. Fiona had told me that her husband would be here looking after their son. I knocked again, this time a little louder. There was still no reply.

As I turned to leave, car lights shone down the lane. Fiona stepped out of a beaten up Toyota, yelled 'thanks for the lift' and then turned to me. 'Sorry I'm late, shall we go in?' I stepped inside and at once knew this was home to snowboarders. Boots, hats and gloves were give away signs, scattered in front of a small wood burner to dry. The remains of dinner were left on the table, a half-empty tin of beans with sausages. 'Sorry about all the mess' Fiona explained 'My husband had to pick [Jamie] up from day care and feed him, he'll have then gone straight back to bed. He starts work soon.' She checked her watch. 'Yeah, I'll have to wake him soon, he starts at eleven, he's only had a few hours sleep'.

Just then, her son [Jamie] appeared from behind the only door leading from the kitchen. He had been sharing his father's bed, the only bed, waiting for his mum to return. He remained with us for the next ninety minutes, enjoying his mum's company, and the 'afternoon tea' of chocolate biscuits and milo that she prepared. As I write this, I am very aware of my own prejudices regarding motherhood. As I said, I was not 'ready'. I had thought I was, but I had not expected [Jamie] to join us for the interview, or to be playing 'trains' at eleven-thirty at night. I 
had not been prepared for the extremely cramped living conditions, or for the carpet that lined the walls to keep them warm. This was not a comfortable middle-class home like the other research participants had lived in. This was a means to an end: a place to sleep when sleep was needed, but, it was no more than that, and it did not need to be. For when Fiona and her husband were not working or sleeping they were up the mountain. I learnt a lot in that ninety minutes, not only about Fiona, but also about myself. This article recounts Fiona's story, yet it is inevitably tinged by my own investments and beliefs about what constitutes 'motherhood' and 'parenting'.

\section{Introduction: It's a 'lifestyle thing'}

In the lifestyle sports literature it has long been acknowledged that 'committed', 'core' or 'serious' participants organise their whole lives around their sport (Ford and Brown, 2006; Thorpe, 2008; Wheaton, 1997, 2004). This includes choosing employment and a place of residence that allows maximum time for participation. For example, Wheaton (1997) found that having 'free time' and flexible working arrangements were 'the most valued commodities' (104) in her study of serious windsurfers. In relation to snowboarding, 'core boarders' tend to follow the snow seasons (Thorpe, 2012, 2017). Indeed, one of the signifiers of status within lifestyle subcultures is related to the experience of travel (Thorpe, 2017, 2015; Wheaton, 1997, 2017; Wheaton and Beal, 2003). Increasing attention has been paid to lifestyle mobilities in action sport cultures over recent years (Porter and Usher, 2019; Rickly, 2016; Thorpe, 2017, 2014; 2012) But what happens when these committed sports participants have children?

Despite the extensive 'lifestyle sports' literature, and the growing body of work focused on 'migrant tourist-workers' (Bianchi, 2000), 'working tourists' (Duncan, 2008), and 'lifestyle travellers' (Cohen, 2009; Cohen, Duncan and Thulemark, 2015) reference to families remains scarce. Porter and Usher's (2019) work is unusual in that it explores the relationship between 
family life cycle and surf travel. Whilst work on lifestyle sports has extended to include a focus on older participants (e.g. Beaumont and Brown, 2015; Wheaton, 2017) and those who have worked in the associated industries for many years (Thorpe, 2015), explicit mention of mothers who have adopted a 'leisure-driven work culture' (Adler and Adler, 1999, 394) or mothers who continue to embrace sport and/or travel as part of their chosen lifestyle is missing. Indeed as I have argued elsewhere, motherhood is a largely invisible concept in relation to lifestyle sports per se $(X X X X($ Spowart and Burrows; 2016; Spowart, Burrows and Shaw,-2010).

Discourses of independent travel and voluntary mobility are most commonly associated with youth (Cohen, 2009; Matthews, 2009). Long-term international travel, and in this the case of this study the pursuit of 'endless winters' ${ }^{1}$, is most commonly regarded as an opportunity for people without family responsibilities, to pursue their dreams and find out about the world and themselves before they transition to adulthood and 'settle down' (Thorpe, 2017). Whilst attention has recently attention has been given to the increasing number of individuals who travel into and beyond their thirties, travel has still been assumed to represent 'a lifestyle alternative for those at least temporarily unencumbered by family and professional responsibilities' (Westerhausen, 2002, 154). For example, in Thorpe's (2017) study of transnational mobilities of skilled snow sports workers, of the two women interviewed for the study- one had relinquished their nomadic lifestyle having started a family, and for the other, the topic was not discussed.ehildren are not mentioned. Drawing on her research over a period of many years Thorpe (2017) notes: 'Many female snowboarding migrants "retire" earlier from the "back-to-back" lifestyle than their male peers'. Developmental discourses clearly contour what is regarded as acceptable travel

\footnotetext{
${ }^{1}$ I use the term 'endless winter' to depict the movement of people who follow the snow season across the globe.
} 
behaviour. Therefore, in choosing to snowboard and travel, mothers must negotiate powerful discourses in relation to the sport itself, motherhood and the associated travelling lifestyle.

\section{Methods}

This paper presents data from just one participant, whom I have called Fiona, drawn from a larger New Zealand based longitudinal study of mothers' engagement in snowboarding between 2007 and 2010, in which participant diaries and a series of in-depth qualitative interviews were completed (Spowart, 2010). In line with the findings of previous lifestyle sports studies, all of the women in this study had travelled abroad to snowboard at least twice during the past ten years to experience the mountains and lifestyle of a range of high profile resorts. Fiona migrated annually between America and New Zealand to maintain her mountain lifestyle.

I focus in on Fiona's story with the intention of providing a rich contextualised account of her experiences as a snowboarding mother and snow sport migrant. These narratives can assist with our understanding of Fiona's attitudes, meanings and values associated with adopting a snowboarding lifestyle involving transnational migration and motherhood. Fiona's accounts elicited by my questions should not be viewed simply as private reactions to personal experiences of travelling and motherhood. Rather, they may be regarded as narratives contoured by discursive resources that are, in turn, shaped by other snowboarders, the industry, and society at large. In analysing Fiona's accounts I adopt a feminist poststructuralist lens to provide a discursive account of motherhood. To this end, I draw on Scott's (1990) definition of discourse as a 'historically, socially, and institutionally specific structure of statements, terms, categories, and beliefs that are embedded in institutions, social relationships, and texts' (135-136). Whilst Fiona's experiences cannot be used to make large-scale generalisations, her experiences may hold significance and meaning for others, and serve to uncover the ways that Fiona attaches meanings to certain activities, behaviours and discourses. In particular, I am interested in the ways that discourses of motherhood, snowboarding, travel, mobility and lifestyle are internalised, resisted 
and transformed in Fiona's everyday life. I pay particular attention to the 'central moments or critical incidents' around 'indecision' and 'contradiction' (Sparkes, 1995, 116), to illustrate the complex processes Fiona engages in.

The data are infused by my own past experiences as a snow sport migrant with 2 young children. As England $(1994,84)$ so eloquently points out: 'We do not parachute into the field with empty head and a few pencils or a tape-recorder in our pockets ready to record the "facts"'. Following the birth of my first child, I experienced many voices of disapproval at my choice to continue participating in snow sports and to travel. 'It's not appropriate anymore', 'You're a mother now', and 'When are you going to grow up?' they cried. Through these personal experiences, I became acutely aware of the developmental expectations that contour the 'appropriate' options afforded to women once they become mothers.

\section{Discourses of work/life}

Before I move to Fiona's narratives, it is important to highlight a number of significant political, economic and social changes that have taken place in Western societies over recent decades. For many, the security of permanent full-time employment has become a thing of the past, as increasing numbers of people are employed on short-term contracts and/or as part-time workers (Beck, 2000; Harris, 2004). In its place, there is a focus on enterprise and individual responsibility, with people expected to "create their own chances and make the best of their lives' (Harris, 2004, 4). This shift in economic and political circumstances has resulted in the boundaries between work and leisure becoming increasingly blurred (Boon, 2006; Stebbins, 2017). While work may remain the central life interest for many, there is growing evidence to suggest that numerous individuals give priority to activities outside of the workplace (Boon, 2006; Casey \& Alach, 2004; Thorpe, 2015). As Campbell (2005) puts it: 'Modern individuals 
inhabit not just an "iron cage" of economic necessity, but a castle of romantic dreams, striving through their conduct to turn the one into the other' (227).

\section{Serious leisure}

The privileging of leisure above other aspects of life has been identified in a study of skiers in New Zealand. In Boon's (2006) study, skiers chose employment that afforded them maximum time on the slopes, deliberately opting for temporary, seasonal work with a high level of flexibility. As a result of her research Boon (2006) asserts that 'it is important to acknowledge that rejection of existing career opportunities is not just about families' (596). Leisure and sport as a central life interest are also significant in determining career patterns, and this aspect is receiving increasing attention in the literature (Maguire and Falcous, 2010; Thorpe, 2017).

Commitment to a particular leisure pursuit, such that involvement impacts upon career pathways, is at the core of the concept of serious leisure, a term first coined by the Canadian sociologist Robert Stebbins in 1982. The term has subsequently been refined into the following definition:

The systematic pursuit of an amateur, hobbyist, or volunteer core activity sufficiently substantial, interesting and fulfilling in nature for the participant to find a career there acquiring and expressing a combination of its special skills, knowledge, and experience. (Stebbins, 2015, 21)

Participants structure their lives in such a way that time and resources are privileged towards their chosen leisure activity. In some cases, commitment is so high that serious leisure becomes the 'central organizing principle in participants' lives' and provides 'the space for them to create distinct social identities' (Raisborough, 2006, 245).

Fiona fits this description well. After completing her degree in 2003, Fionashe travelled from New Zealand to Colorado to work as a snowboard instructor. She was twenty-one years 
old. It was here she met her husband, also a snowboarder, who was working as a night groomer. ${ }^{2}$

Since then the couple has migrated between Colorado and Queenstown, to pursue their passion for snowboarding. To sustain their lifestyle, they gain seasonal employment that allows them to achieve precious time on the snow. Salaries are less important. As Fiona explained: 'As long as we have enough money to pay for a roof over our heads and feed ourselves, we're happy'.

For Fiona and her husband, travelling from season to season has become part of their identity as snowboarders. Furthermore, unlike many people who experience travel as a break from normality, for Fiona, regular migration between mountain resorts around the globe was more akin to the experiences of Welk's (2004) long-term backpackers. That is to say, the travel and the transient lifestyle 'is not designed to be an interruption from normality, it is normality' (Welk, 2004, 90, emphasis added). For instance, when I asked Fiona what snowboarding meant to her she replied:

Um, LIFESTYLE, pretty much. It brought us together and we're still trying to continue on with it. Definitely, yeah, a lifestyle. We plan our whole lives around it you know? Work, where we live, and everything. We probably don't get as much riding as we would like to anymore, just because of having a child and doing night shifts and things like that but you know, you've got to make these choices sometimes, but we still try and live the same lifestyle. It's just a matter of priorities really and snowboarding's important to us you know?

Unlike many women who are drawn to 'settling down' when they plan to have children (Brannen \& Nilsen, 2002), Fiona's life is shaped around her snowboarding and transnational migration to avoid 'miss[ing] a season'. For Fiona, the adoption of a life in which snowboarding remains central is just a matter of personal choice. However, Fiona's lifestyle decisions may not be as straightforward as she posits. R, rather, Fiona actively draws on neoliberal discourses of

\footnotetext{
${ }^{2}$ A groomer is the name given to a person who maintains the ski hills, trails and snow parks by using a vehicle to move, flatten and shape the snow. The groomers drive large heavy plant machinery such as snow ploughs, tractors, trucks or snowcats towing specialised equipment. Because the slopes are busy during the day, the job is mainly undertaken at night.
} 
individualism and sub-cultural discourses (e.g. snowboarding, lifestyle and feminism) to craft her 'self' in complex and often contradictory ways.

Despite acknowledging that things have become more difficult now that she has a child, Fiona assumes responsibility for the lifestyle choices that she has made in having a child and choosing to work shifts. She implies that by prioritizing certain aspects of her life, she can maintain her snowboarder lifestyle, and maintain a sense of happiness in her life.

When I'm home with [Jamie, her son] I just seem to be doing housework, or playing with [Jamie], or sleeping (laughs). I can spend all day being busy, and I'm always tired, but I look back on my day and I often think: what have I done all day? What have I actually achieved? I NEVER feel like that with snowboarding. Even when I've had a poor day, you know hurt myself, or not ridden so well, I still feel like I've at least achieved something.

Here Fiona conveys her need for a sense of achievement and a tangible measure of improvement that she does not necessarily acquire in her day to day life as a mother. Strategies deployed in the policy arena, such as policies aimed at work/life balance, and equal opportunities policies 'work not only to mobilize the subject's capacity to govern itself", but to enact leisure and lifestyle decisions 'in the name of freedom and choice'(Fullagar, 2002, 71). Adopting a neoliberal lens, Fiona's snowboarding lifestyle involving transnational migration may be understood to be political in the sense that it constitutes a neoliberal practice implicated in the everyday practices of crafting the self (Foucault, 1978).

Adopting a Foucauldian approach, Rose (1999) argues that neoliberalism is much more than a philosophical principle aimed at restricting the level of government intervention. Instead, social subjects are mobilised through political strategies directed at self-governance (Foucault, 1991). The promotion of self-governance is in itself a powerful technique through which to govern the population. Individuals must develop strategies for their own success and happiness and take responsibility for their actions (Harris, 2004). Herein lies the paradox, not only are 
people expected to choose, but they are required to choose in order to be 'free' (Rose, 1999, 268).

Whilst neoliberalism "can be understood in terms of political rationalities and political technologies" (Nairn and Higgins, 2007, 262), I do not wish to suggest that the state somehow 'forces' people to behave in certain ways. On the contrary, it is important to recognise that 'people are active subjects within neoliberal discourses' (Nairn and Higgins, 2007, 262), and engage with a complex network of other, sometimes contradictory, discourses to constitute themselves. My reading thus far of Fiona as an individualised subject who is able to create a lifestyle through snowboarding is far too simplistic. There are ${ }_{2}$ for example, important intersections between neoliberalism and feminist identities (Rich, 2005) which I explore in the next section.

\section{'Grab life and go for it'...Just like Torah Bright}

It is not insignificant that Fiona was the youngest of the participants in this study being born in New Zealand in 1982, and growing up amidst powerful discourses of equality and limitless choice. As numerous writers have commented, young women in the 1990s and early twenty-first century have been subjected to a proliferation of messages promoting empowerment and the realisation of one's dreams (see for example: Harris, 2004; Walkerdine, 2003). The status of women in both the education and employment sectors has shifted dramatically over recent years, enabling Fiona's generation to view themselves as free to make career and lifestyle choices previously not available to themearlier generations. Simultaneously, the phenomenon of 'Girl Power'3 took hold 'entering mainstream cultural arenas through an incredible range of

3 'Girl Power' as a political rhetoric is widely believed to have originated in the US punk rock music scene in the early 1990s. For a detailed historical account of the Girl Power movement see Gonick (2006) and Kearney (1998). 
products and services' (Gonick, 2006, 8). Bands like The Spice Girls promoted equal rights for girls and women, and whilst not without their feminist critics, had the effect of 'bringing feminism into the lives of young women' (Gonick, 2006, 9). In short, young women have been told they can be who they want to be (Gonick, 2006).

At around the same time as The Spice Girls reached their peak in the late 1990s, the release of female only snowboarding films such as Dropstitch helped to promote the nomadic snowboarding lifestyle for women. This corresponded with the more widespread circulation of discourses promoting the creation of a life worth living. Within this cultural context, an influential figure in Fiona's life has been the Australian born snowboarder, Torah Bright. Torah is one of the most dynamic snowboarders in the world, and at the time of interview was the highest earning Australian sportswoman of all time (Stanley, 2009). She is Australia's most successful athlete at the Winter Olympics and in 2014 became the first Olympic athlete (male or female) to qualify for all three snowboarding disciplines. In 2003, when Fiona first travelled to America to snowboard, Torah was making headlines. Fiona explained her fascination with Torah like this:

Fiona: Every girl that snowboards wants to be like Torah. She's amazing. Like she's just a cool chick from a small town in Oz who loves to ride. She's all about family and stuff but she's also got this really cool lifestyle travelling the world.

Interviewer: So what is it about her that you like?

Fiona: Oh you know, she's just really down to earth, afraid of nothing and yeah, I think she just shows what women can do these days. Like she earns more money than most men will ever dream of earning, and yet she seems so down to earth still. And best of all, she's earning money doing what she loves, like that's pretty neat. Interviewer: Have you ever met her?

Fiona: I've seen her compete quite a few times. Like she spends a lot of her time in New Zealand training and competing in our winter, and then she goes to the States for their winter. I've not spoken to her but everyone I've spoken to who knows her says she's just a really cool chick. But you know not just on the slopes but in life you know, she's just inspiring. Interviewer: In what way? 
Fiona: Like she just seems to grab life and go for it. I love that attitude in people. Like you know, you've gotta make your own luck in life. She [Torah] wasn't born to be a snowboarder, she's put in the hard graft, like God knows how many hours she will have spent practising and falling and picking herself up and going for it again, and now it's paying off you know?

In her talk, Fiona alludes to the increasing opportunities for women that have arisen over the generations, noting that it 'just shows what women can do these days'. However, rather than attribute Torah's success to social change, and the increasing opportunities for women more generally resulting from the impact of feminist politics, Fiona draws upon the ideals of the neoliberal subject who 'make[s] [their] own luck' in life. In so doing, she appears to assume that everyone is free from the 'traditional ties of location, class and gender' and is ‘completely self-produced' (Walkerdine, 2003, 240).

Larner (2000) points out that the conception of individuals as active agents responsible for their own destinies 'can also be linked to a particular politics of the self in which we are all encouraged to 'work on ourselves' in a range of domains, including the counter-cultural movements outside the purview of traditional conceptions of the political' (13). For Fiona, this 'work' includes creating her life as a snowboarder, pursuing her dreams of travel and developing her skills in the terrain park. Choice and self-invention are central to the ways in which Fiona considers her life. This notion of choice extends to all areas of her life, and does not and should not stop just because she has a child. To Fiona, Torah Bright 'has it all'. Fiona makes no secret of her desire to live a lifestyle that is similar to Torah's, or at least, how she imagines it to be.

In spite of having a three year old child, Fiona yearns for the glamorous 'cool lifestyle' of a younger, child-free woman like Torah. She wants to be a good snowboarder, a good mum and travel the world, and she seems convinced that if you work hard enough, these dreams can become a reality. There are advantages to this position, in that it enables Fiona to negotiate access to whatever she wants to do. Her decision to continue living the 'snowboarding lifestyle' during and following her pregnancy stands in testimony to this. However, this position also 
'rather problematically obscures underlying social structures' (Rich, 2005, 501). Furthermore, in drawing on neoliberal discourses of 'having it all' lack of success is likely to be attributed to personal failings rather than societal constraints.

Thus far, I have discussed the economic, social and cultural conditions that have produced a climate in which leisure has increasing prominence. I have also described the changing social conditions for girls and women, and the prominence of role models like Torah Bright. These role models invite and persuade other women to imagine themselves living the glamorous lifestyle associated with snowboarding and travel. Girls are encouraged to 'be who they want to be', and this discourse is evident throughout Fiona's talk. The desire to live a life that is meaningful, and not centred purely on paid work is tied to increasingly 'mobile lifestyles'. In the context of the snowboard industry, this often leads to a process of continual migration. In the next section I focus on Fiona's experiences of combining travel, work, snowboarding and motherhood.

\section{Discourses of travel and mobility}

I asked Fiona to recount what could be termed a 'critical incident' (Sparkes, 1995) in her life.

This was her decision to continue travelling once she became pregnant. For many women this is a period in their lives when they seek stability. The conversation progressed in the following way:

I couldn't bear to miss a season, but I was lucky. I got pregnant in May 2004 and boarded the winter season in New Zealand and worked as an instructor until I was about five months pregnant. I didn't really show at all because my big jacket and snowboard pants hid my bump (laughs), so no-one asked any questions, and I didn't tell anyone. We then moved to Colorado in October for their winter. I was too big by the time we got there but I had [Jamie] in January and then I was snowboarding two weeks later. The season runs right through to March/April there so I still got a lot of time riding (pauses). It didn't really enter our heads to stop doing what we do. It's just our way of life you know? We love the freedom it gives us, you know the flexibility? We don't really see it as unusual...(pauses), or at least, we didn't then. Snowboarding is how my husband and I met, it's what we both love to do, it makes us both happy and we have built our life around it. I'm not ready to be tied down yet (laughs). 
It is rather intriguing that Fiona does not regard herself as 'ready to be tied down' 2 a term traditionally associated with marriage. Yet Fiona married in 2004 shortly after she became pregnant. Her comments point to the changing economic, political and social climate, and the increased opportunities for crafting oneself 'independently of the traditional ties', such as work and family responsibilities, 'previously...so instrumental in structuring life trajectories' (Rich, 2005, 4). The central place of snowboarding in Fiona's life is once again emphasised in this quote, as she reflects upon her good fortune at the timing of her pregnancy. The fact that it 'didn't really enter [Fiona's] head' to stop snowboarding and travelling points to the 'discursive formations' (Foucault, 1985) already circulating, which determine what it is possible for Fiona to be. Fiona expresses a sense of entitlement to happiness that reflects the moral imperative to live life to the full, to be happy and take responsibility for the choices that you make.

\section{'We can just get up and go'}

Travel experiences can assist in the creation of a unique and successful self-identity. Like many young travellers, Fiona reveals a concern with accumulating new experiences, and a desire to escape the mundane and routine aspects of life (Duncan, 2008; Matthews, 2009). Furthermore, like the respondents in Wheaton's (1997) study of windsurfing, and Thorpe's (2017) study of snow sport workers, working a nine-to-five job is represented as the antithesis of the freedom Fiona aspires to secure. Fiona values the flexibility that temporary seasonal employment affords her, and is not 'ready to get too serious about work', and in so doing, draws on discourses of youth, and developmental assumptions regarding work. She also attests to liking the freedom and flexibility she gets from living in temporary rented accommodation.

Fiona: I feel that I'm not tied to one job or place or even people. We don't own anywhere, which at the moment we see as a good thing. Like we can just get up and go when we want to, more or less, you know? (pauses) Um, and our work is pretty flexible, well I mean [Rob] has to work nights which isn't always great but it means he can board in the day, and it also means he is home to look after [Jamie] if I'm at work. 
He gets two nights off a week which is great and if the snow's real good he'll stay up the mountain and meet me up there. You know, like he won't sleep until we've boarded for a few hours. So it beats working 9 to 5. I couldn't bear that same old same old.

From my discussions with Fiona, it is clear that, at times, her economic status impacts upon her snowboarding. However, Fiona and her husband adapt their lives to counter this. Fiona regularly hitch hikes to work and to the mountains, and keeps other costs such as rent, heating, food and clothing to a minimum. Both Fiona and Rob, her husband, also receive non-monetary incentives at work which Fiona regards as an attractive aspect of their respective positions.

People think you have to be rich to snowboard but when you work here it's different. Like, sure, you'd have to be rich to come on holiday here (referring to Queenstown), but most snowboarders aren't like that. Like, we get a job and it's enough to allow us to board. I've got it pretty good because my hours...well most of the time anyway... allow me to board, and plus, I get discounted gear from the shop, and we always get perks...especially at the end of the season. Like, I never have to pay to get my board edged or waxed or anything. They just see to it which is pretty cool.

Fiona's comments about not needing to be 'rich' are important given the middle-class status of snowboarding (Donnelly, 2006; Heino, 2000; Thorpe, 2017). For 'core' boarders, like Fiona, it is not money that is important. On the contrary, there appears to be some kudos attributed to doing things the hard way and living on a very tight budget. Rather than money, time is the most valued commodity, for time equates to freedom to snowboard. Consequently, snowboarders often brag about their days spent on the mountain. Fiona proceeded to explain the perks of her husband's job as a groomer:

As a groomer, you get a season pass, that's the wicked thing about that job. So, yeah, Rob can board any time he's not working which is cool ey? He also gets pretty good gear. Like he gets all his uniform which is good gear. Full gore-tex and mountain boots, gloves and stuff, um, yeah, and he also gets free transport to work from just up there on the road so that's pretty good. We don't really need much other than our board and boots. And cos Rob's a returning staff member I get a reduced pass, and [Jamie] gets discounted childcare.

It is not uncommon for tourism employers to offer a range of benefits to help recruit and retain good staff. In the ski and snowboard industry one of the biggest 'perks' on offer is a season lift pass. Whilst we did not discuss salaries, generally speaking wages for seasonal resort workers are low (Duncan, 2007; Thorpe, 2017). Perks such as free lift passes therefore entice employees 
to the often harsh working conditions associated with mountain resorts. In Rob's line of work, there is nothing very glamorous about driving heavy plant machinery around steep mountainsides in the dark and wintery conditions. The work is long and conducted during unsociable hours, it is also dangerous and poorly paid. In spite of this, Fiona maintains that 'being in the mountains, hanging with mates, and avoiding the stresses of "normal life"' makes it all worthwhile. Travel is an integral part of this lifestyle, which Fiona constructs as the discursive opposite of a 'high-powered' career.

\section{'New people, new places': Great for a kid, don't you think?}

The benefits of travel are important to Fiona, not only for her own self-development, but also for her son's. Travel is commonly regarded as one way to enhance career prospects by gaining a diverse range of experiences and to develop a sense of self (Bell, 2002; Duncan, 2008).

Consequently, Fiona justifies her snowboarding lifestyle as providing Jamie with an induction into a life likely to be full of perpetual change.

A lot of my friends like they've never left New Zealand you know? Like they haven't even been to Auckland actually (laughs), they have no idea about anything other than home. I wouldn't want to be like that and I don't want [Jamie] to be either. Like he has travelled a lot already and he's only three. He is used to change and I think that's a good thing you know?

Fiona's comments are reflective of a postmodern concern with accumulating a range of travel and cultural experiences (Matthews, 2009). Travel, and in particular 'authentic travel' is an important marker of class, social status and lifestyle (Cohen, Duncan and Thulemark, 2015; Duncan, 2007; Urry, 2002). As Urry $(2002,4)$ explains, travel 'has become a marker of status in modern societies and is also thought to be necessary for good health'. Here Fiona constructs travel as an educational tool via which Jamie can participate and interact, and in so doing, acquire knowledge of a range of contexts outside of New Zealand, preparing him for a world lacking stability and coherence. 
The idea of authenticity has been a concern in travel and tourism studies for over 30 years

(Hall, 2007). Travel experiences that are regarded as 'culturally rewarding, environmentally

friendly, and socially benign for host communities' (Kontogeorgopoulos, 2003, 172), are often

regarded as being 'more authentic' experiences than those associated with mass tourism.

Kontogeorgopoulos (2003) argues that the preference of the new middle classes have shaped the discourse of travel authenticity.

For Fiona, the abject body (Kristeva, 1982) is the person who has not experienced other places within their country of birth, let alone elsewhere in the world. Again, there is evidence of a neoliberal attitude, where the individual who stays at home is held responsible for their decisions not to travel. The unbounded possibilities of international travel are assumed to be universally attainable. In reality, the 'OE' (Overseas Experience) is predominantly undertaken by middle-class, Pākehā (white), New Zealanders. For this group, the 'OE' has become such a 'cultural institution', that to remain in New Zealand requires justification (Bell, 2002). Fiona explains what she liked about living in two countries:

Fiona: I love the unpredictability of it all. You know, we arrive in a resort, we don't usually know where we are going to be staying. It's exciting, it's a challenge, you can't get in a rut because things are constantly changing. You know? The people change...well, some anyway (laughs), our home changes, my work usually changes...everything really, yeh, it's exciting. Interviewer: Yeah, sure, but it must be pretty nerve racking with [Jamie]?

Fiona: Yeah, sometimes. Like, I did get a bit stressed when we came here, but it worked out in the end you know? My husband's pretty mellow so that helps, and we've done it all before so many times, it's just part of it. Part of the lifestyle. You just get used to it and you get better at dealing with change. Actually, I think that's one of the great things about it, we are all pretty adaptable. Like [Jamie] doesn't get phased by much, you know? Like other parents won't go here and won't go there, like their kids are in such a strict routine that they can't seem to do anything you know? So, what happens when they have to do something different? How will they cope you know? (Laughs) From what I see, they usually don't...like everyone gets stressed and no-one can deal with it. [Jamie] just takes it all in his stride. He loves it, it's exciting and new. New people, new places, I think that's great for a kid to experience don't you?

Alongside Fiona's passion for snowboarding, and travel, she expresses other more pragmatic advantages she believes her lifestyle affords her and her family. In this excerpt Fiona draws on discourses of 'good parenting' and the 'independent child', as a justification for her nomadic lifestyle. To Fiona, their lifestyle affords them the opportunity of raising a son who is 
adaptable, and can deal with change. Flexibility and adaptability have entered into the discourse of social and economic policy, and are deemed to be important assets in a world full of uncertainty. As Walkerdine (2003) explains: 'It is the flexible and autonomous subject who is demanded to be able to cope with constant change in work, income and lifestyle, and with constant insecurity' (240). This is a helpful discourse through which to bolster Fiona's decisions to keep on travelling and conveniently re-frame her position as a transient snowboarder, as something that contributes to her capacity to perform as a 'good mother'.

\section{Living a transient snowboarding lifestyle: Freedom or constraint?}

Despite the flexibility of Fiona's part-time seasonal working arrangements and the experiences of liberation that she expresses, it is clear that neither Fiona nor her husband are 'free' from their everyday concerns of work and childcare, nor the risks involved in undertaking temporary work of this nature. Fiona's diary entries reveal the hard work that is invested in maintaining her nomadic mountain lifestyle that, at times, contradicts the romantic notion of freedom she presents. She writes:

I have been working 2 jobs this week - looking up at the mountains with envy as there have been so many beautiful days in a row. So today was welcomed and I was very energised to be out snowboarding.

Employment in tourist destinations such as mountain resorts is commonly associated with long hours and low salaries (Duncan 2007; Thorpe, 2017). In this particular week, Fiona admitted to working seven evening shifts at a snowboard shop from $3 \mathrm{pm}$ until $10.30 \mathrm{pm}$, combined with a number of early morning shifts at a local café. During this time, Jamie's care had to be carefully negotiated between Fiona, her husband and paid childcare. So, whilst snowboarding is presented as Fiona's central life interest, and contours some major life-decisions such as where she lives and the types of employment that she chooses, the relationship between work and leisure is exceedingly complex. For this week, at least, work appears to be the driving force. As Fiona 
admitted, with no savings in the bank, and a child to support, she 'won't turn work down, regardless of the snow conditions'.

Several of Fiona's diary entries also point to the loneliness and sense of displacement she experiences as a young mother in a ski resort.

As I have a son and work in town and have only a few friends here, I don't really have anyone else to go snowboarding with and so for my husband to give up sleeping to come snowboarding with me means a lot.

Today I decided to take on the adventure without my husband's help. I called a friend to see where she was riding and offered her a lift. She had a ride sorted and so I expected her to suggest a time to meet up but she didn't. This made me realise that I'm not the easiest person to make plans with, because I have a child.

As these excerpts reveal, pursuing a lifestyle that necessitates the frequent expense of international travel, childcare costs, and social isolation does not appear to be an 'easy option'. In many ways, these diary entries are quite distinct from the 'freedom' and flexibility Fiona describes earlier. As Rich (2005) points out in her analysis of young women's lives, despite drawing on discourses of individualism, 'the opportunities for self-invention...exist within circumstances that remain highly constrained' (5).

The precariousness of Fiona's situation is exacerbated by the fact that neither Fiona nor her husband have any medical or travel insurance. So, if either of them suffers a fall whilst snowboarding that renders them unable to work, they have nothing to fall back on, and hence a very real prospect of poverty. Within Fiona's narratives are areas of tension and conflict that coexist with her 'grab life and go for it' attitude expressed earlier. In particular, her insecurities are revealed through her diary writings as the season progresses, and I note a change in her attitude towards snowboarding.

Whilst, living precariously has legitimacy amongst travellers (Duncan, 2007), as people age, and particularly when children are involved, expectations shift, and status and authority become increasingly important (McRobbie, 2002). That is to say, 'the technologies of self themselves undergo substantial modification to ensure middle-aged economic well-being' 
(McRobbie, 2002, 110). Like the majority of backpackers in previous travel research (Cohen, 2009; Westerhausen, 2002), Fiona does not regard her current lifestyle as a feasibly indefinite alternative to a 'normal' career, and she expects to re-join the workforce in her home context of New Zealand.

During the course of this research it seems that the problem of 'having it all' has begun to surface in Fiona's life. Instead of effortlessly combining motherhood, snowboarding and a life involving transnational migration, a more feasible long-term option appears to be putting travel 'on hold' whilst she embarks on a postgraduate qualification, and Jamie attends school. She seemed sad as she talked to me, perhaps reconciling her expectations of living the lifestyle of Torah Bright with a quite different reality.

\section{Conclusion}

The status of women in education and employment sectors has shifted dramatically. In the cultural arena too, girls have been told they can be who they want to be (Gonick, 2006). As a consequence, for young women in contemporary Western societies processes of individualisation mean that there is an extensive range of options to choose from. That said, Rose (1991) points to the largely illusory nature of these options, and reminds us that:

$[\mathrm{H}]$ owever apparently external and implacable may be the constraints, obstacles and limitations that are encountered, each individual must render his or her life meaningful, as if it were the outcome of individual choices made in the furtherance of a biographical project of self-realization. (12)

In this way, people are governed through their dreams and aspirations, rather than in spite of them. However, the notion of freedom seems plausible because neoliberal discourses work to persuade us that we are in charge of our own destinies and can shape the conditions of our lives (Baker, 2010). As Fiona's talk illustrates, the neoliberal injunction, that we can be who we want to be, has also found its way into the snowboarding media, and influences people's aspirations via snowboarding role models such as Torah Bright. 
Snowboarding films, magazines, and social media promote the nomadic lifestyle (Thorpe, 2016;

Stone \& Horne, 2008; Wheaton \& Beal, 2003) with exotic images of participants boarding in perfect powder conditions. Enticed by such images and the sense of freedom they portray, increasing numbers of snowboarders migrate across national boundaries (Thorpe, 2017).

Extensive travel symbolises a commitment to sport, and participants are often held in high regard if they 'drop out' of mainstream culture to dedicate a significant amount of time to their sport (Wheaton, 1997; Rickly, 2014; Thorpe, 2017).

However, it is clear from Fiona's narratives that she finds it increasingly difficult to maintain her transient lifestyle for a number of reasons. Firstly, she is no longer the 'same' as her snowboarding friends, by virtue of having a child. As a consequence, she perceives that she is constructed as 'Other', and is often excluded from the group. Secondly, she is concerned about Jamie's long-term future if she and her husband continue to migrate. In particular, issues surrounding his schooling play on her mind. As Weedon $(1987,95)$ points out:

In principle the individual is open to all forms of subjectivity, in reality individual access to subjectivity is governed by historically specific social factors and the forms of power at work in a particular society. Social relations, which are always relations of power and powerlessness, between different subject positions, will determine the range of subject positions open to any individual on the basis of gender, race, class, age, cultural background.

Based on Fiona's narratives, arguably motherhood should be added to Weedon's list. Ironically, despite her passion for travel and snowboarding, Fiona's life-vision appears to be slipping closer to dominant societal norms. For Fiona, it seems that the hybrid identity of snowboarding mother became increasingly difficult to 'perform'. I feel touched by Fiona's story, and realise that the internal judgements that I made in her rented flat are a part of the problem. It is tough to work against the grain, to always be the 'Other'. Whilst Fiona's story cannot be used to make large scale generalisations it goes some way to answer the call for future research that 
expands our understanding of sports migration and lifestyle mobilities beyond the sporting elite

(Newman and Falcous, 2012; Thorpe, 2017). 


\section{References:}

Adler, Patricia A, and Peter Adler. 1999. "Resort Workers: Adapations in the Leisure-Work Nexus." Sociological Perspectives, 42 (3): 369-402.

Baker, Joanne. 2010. "Great Expectations and Post-Feminist Accountability: Young Women Living Up To The 'Successful Girls' Discourse." Gender and Education, 22(1): 1-15.

Beaumont, Emily, and David H. Brown. 2015. "Once a Local Surfer, Always a Local Surfer': Local Surfing Careers in a Southwest English Village.” Leisure Sciences 37 (1): 68-86.

Beck, Ulrich. 2000. The Brave New World of Work. Cambridge: Polity Press.

Bell, Claudia. 2002. "The Big 'OE': Young New Zealand Travellers as Secular Pilgrims.” Tourist Studies, 2(2): 143-158.

Bianchi, Raoul, V. 2000. "Migrant Tourist-Workers: Exploring the 'Contact Zones' of Post-Industrial Tourism." Current Issues in Tourism, 3 (2): 107-137.

Boon, Bronwyn. 2006. "When Leisure and Work are Allies: The Case of Skiers and Tourist Resort Hotels." Career Development International, 11(7), 594-608.

Brannen, Julia, and Nilsen, Ann. 2002. "Young People's Time Perspectives: From Youth to Adulthood." Sociology 36 (3): 513-537.

Campbell, Colin. 2005. The Romantic Ethic and Spirit of Modern Consumerism. $3^{\text {rd }}$ ed. Oxford: Basil Blackwell.

Casey, Catherine, and Alach, P. 2004. "Just a Temp?: Women, Temporary Employment and Lifestyle." Work Employment Society, 18(3), 459-480.

Cohen, Scott A. 2009. The Search For 'Self' For Lifestyle Travellers. Unpublished Doctoral Cohen, Scott A. 2009. The Search For 'Self' For Lifestyle Travellers. Unpublished Doctoral Cohen, Scott A. 2009. The Search For 'Self' For Lifestyle Travellers. Unpublished Doctoral

Cohen, Scott A, Tara Duncan and Maria Thulemark. 2015. "Lifestyle Mobilities: The Crossroads of Travel, Leisure and Migration." Mobilities, 10 (1): 155-172.

Donnelly, Michelle. 2006. "Studying Extreme Sports: Beyond The Core Participants." Journal of Sport and Social Issues, 30(2): 219-224.

Duncan, Tara. 2008. "The Internationalisation of Tourism Labour Markets: Working and Playing in a Ski Resort.” In International Business and Tourism: Global Issues, Contemporary Interactions edited by T. Coles and M. Hall, 181-199. London: Routledge.

England, Kim. 1994. "Getting Personal: Reflexivity, Positionality, and Feminist Research." Professional Geographer, 46(1), 80-89.

Ford, Nicholas J., and David Brown. 2006. Surfing and Social Theory: Experience, Embodiment and Narrative of the Dream Glide. London: Routledge.

Foucault, Michel. 1991. "Governmentality." In The Foucault effect: Studies in Governmentality, edited by G. Burchell, C. Gordon and P. Miller, 87-104, London: Harvester Wheatsheaf.

Foucault, Michel. 1985. The Use of Pleasure. The History of Sexuality Volume Two. London: Penguin.

Foucault, Michel. 1978. The Will to Knowledge: The History of Sexuality Volume 1. London: Penguin.

Fullagar, Simone. 2002. "Governing the Healthy Body: Discourses of Leisure and Lifestyle within Australian Health Policy." Health: An Interdisciplinary Journal for the Study of Health, Illness and Medicine, 6(1): 69-84.

Gonick, Marnina. 2006. "Between 'Girl Power' and 'Reviving Ophelia': Constituting the Neoliberal Girl Subject.” NWSA Journal, 18(2): 1-23.

Hall, Michael C. 2007. "Response to Yeoman et al: The Fakery of the 'Authentic Tourist'." Tourism Management, 28(4): 1139-1140. 
Harris, Anita. 2004. Future Girl: Young Women in the Twenty-First Century. New York and London Routledge.

Heino, Rebecca. 2000. "What Is So Punk About Snowboarding?” Journal of Sport and Social Issues, 24(1): 176-191.

Kontogeorgopoulos, Nick. 2003. "Keeping Up With the Joneses: Tourists, Travellers, and the Quest for Cultural Authenticity in Southern Thailand." Tourist Studies, 3(2), 171-203.

Kristeva, Julia. 1982. Powers of Horror: An Essay on Abjection. New York: Columbia University Press.

Larner, Wendy. 2000. “Neo-Liberalism: Policy, Ideology, Governmentality.” Studies in Political Economy, 63: 5-25.

Matthews, Amie. 2009. "Living Paradoxically: Understanding the Discourse of Authentic Freedom as it Emerges in the Travel Space." Tourism Analysis, 14, 165-174.

Maguire, Joseph and Mark Falcous. 2010. Sport and Migration: Borders, Boundaries and Crossings. London: Routledge.

McRobbie, Angela. 2002. "From Holloway to Hollywood: Happiness At Work in the New Cultural Economy." In Cultural Economy: Cultural Analysis and Commercial Life, edited by P. du Gay and M. Pryke, 97-114. London: Sage.

Nairn, Karen, and Jane, Higgins. 2007. "New Zealand's Neoliberal Generation: Tracing Discourses of Economic (Ir)Rationality." International Journal of Qualitative Studies in Education, 20(3): 261-281.

Newman, J., and Mark Falcous. 2012. "Moorings and Movements: The Paradox of Sporting Mobilities." Sites 9 (1): 38-58.

Porter, Brooke A., and Lindsay E. Usher. 2019. "Sole Surfers?: Exploring Family Status and Travel Behaviour Among Surf Travellers", Annals of Leisure Research 22 (4): 424-443.

Raisborough, Jayne. 2006. "Getting Onboard: Women, Access and Serious Leisure." The Sociological Review, 54(2): 242-262.

Rickly, Jillian M. 2016. "Lifestyle Mobilities: A Politics of Lifestyle Rock Climbing." Mobilities 11 (2): 243-263.

Rich, Emma. 2005. "Young Women, Feminist Identities and Neo-Liberalism.” Women's Studies International Forum, 28(6): 495-508.

Rose, Nikolas. 1999. Powers of Freedom: Reframing Political Thought. Cambridge: Cambridge University Press.

Scott, Joan W. 1990. "Deconstructing Equality-Versus-Difference: Or, The Uses of Poststructuralist Theory For Feminism." In Conflicts in Feminism, edited by M. Hirsch and E. F. Keller, 134-148. New York: Routledge.

Sparkes, Andrew. C. 1995. "Living Our Stories, Storying Our Lives, and the Space in Between: Life History Research As a Force For Change." In Research in Physical Education and Sport: Exploring Alternative Visions edited by A. C. Sparkes, 74-89. Lewes: Falmer Press.

Spowart, Lucy, 2010. Snowboarding Mums Carve out Fresh Tracks: Collective Stories from the Mountains of Aoteoroa/New Zealand. Unpublished Doctoral Dissertation, University of Otago, Dunedin.

Spowart, Lucy, and Lisette Burrows. 2016. "Negotiating Moral Terrain” In Women in Action Sport Cultures: Identity, Politics, Experience and Pedagogy, edited by H. Thorpe and R. Olive. Houndsmills, UK: Palgrave Macmillan.

Spowart, Lucy, Lisette Burrows and Sally Shaw. 2010. "I Just Eat, Sleep and Dream of Surfing': When Surfing Meets Motherhood." Sport in Society 13 (7-8): 1186-1203.

Stebbins, Robert A. 2017. Between Work and Leisure: The Common Ground of Two Separate Worlds. London: Routledge.

Stebbins, Robert A. 2015. Serious Leisure: A Perspective for Our Time. New Brunswick: Transaction Publishers.

Stone, Jacqui, and John Horne. 2008. "The Print Media Coverage of Skiing and Snowboarding in 
Thorpe, Holly. 2016. "Action Sports, Social Media, and New Technologies: Towards a Research Agenda." Communication and Sport. https://doi.org/10.1177\%2F2167479516638125

Thorpe, Holly. 2008. Boarders, babes and bad-asses: Theories of a physical youth culture. Unpublished Doctoral Dissertation, University of Waikato, Waikato.

Thorpe, Holly. 2017. “'The Endless Winter”: Transnational Mobilities of Skilled Snow Sport Workers." Journal of Ethnic and Migration Studies 43 (3): 528-545.

Thorpe, Holly. 2014. Transnational Mobilities in Action Sports Cultures. Houndmills, UK: Palgrave Macmillan.

Thorpe, Holly. 2012. "Transnational Mobilities in Snowboarding Culture: Travel, Tourism and Lifestyle Sport Migration." Mobilities 7 (2): 317-345.

Thorpe, Holly. 2015. "Understanding Snowboarding Bodies With Bourdieu." In Pierre Bourdieu and Physical Culture, edited by Lisahunter, Wayne Smith, and Elke Emerald, 134-142. Abingdon, OX: Routledge.

Urry, John. 2002. The Tourist Gaze, $2^{\text {nd }} e d$. London: Sage.

Walkerdine, Valerie. 2003. "Reclassifying Upward Mobility: Femininity and the Neo-Liberal Subject." Gender and Education, 15(3): 237-248.

Welk, Pete. 2004. "The Beaten Track: Anti-Tourism as an Element of Backpacker Identity Construction." In The Global nomad: Backpacker travel in theory and practice, edited by G. Richards and J. Wilson, 77-91. Clevedon: Channel View Publications.

Westerhausen, Klaus. 2002. Beyond the Beach: An Ethnography of Modern Travellers in Asia. Bangkok: White Lotus Press.

Wheaton, Belinda. 1997. Consumption, Lifestyle and Gendered Identities in Post-Modern Sports: The Case of Windsurfing. Unpublished Doctoral Dissertation, University of Brighton, Brighton.

Wheaton, Belinda. 2017. "Surfing Through the Life-Course: Silver Surfers' Negotiation of Ageing." Annals of Leisure Research, 20 (1): 96-116.

Wheaton, Belinda, ed. 2004. Understanding Lifestyle Sports: Consumption, Identity and Difference. London: Routledge.

Wheaton, Belinda, and Becky Beal. 2003. "'Keeping it real': Subcultural media and the discourses of authenticity in subcultural sport." International Review for the Sociology of Sport, 38(2), 155-176. 